\title{
No hay crisis inútil
}

\author{
Beatriz Oropeza Villalobos
}

\section{Resumen}

La situación sanitaria actual ha generado aprendizajes valiosos para todos, incluidos nosotros los docentes. Muchos hemos optado por resistir esta crisis y convertirnos, en un período muy corto, en docentes aprendices de las Tecnologías de la Información y la Comunicación (Tіc) y ejercer la Enseñanza Remota de Emergencia (ERE), con el objetivo de atender a nuestros estudiantes y apoyar su aprendizaje a pesar de las circunstancias. El presente testimonio narra lo que he experimentado en este período, desde enfrentar las tareas con temor e incertidumbre, hasta la satisfacción de haber adquirido importantes y significativos aprendizajes, de manera rápida.

Palabras clave: docente, aprendiz, TIC, enseñanza remota de emergencia.

\section{THERE IS NO USELESS CRISIS}

\begin{abstract}
The current sanitary situation has generated valuable learning for everyone, including us teachers. Many of us have chosen to resist this crisis and become, in a very short period, teachers who are also apprentices of Information and Communication Technologies (ICT) and that are practicing the Emergency Remote Teaching (ERE), with the aim of serving our students and support their learning, regardless of the circumstances. This testimony narrates what I have experienced in this period, from facing tasks with fear and uncertainty, to the satisfaction of having acquired important and significant lessons, quickly.
\end{abstract}

Keywords: teacher, apprentice, Ict, emergency remote teaching.

Recepción: 20/10/2020. Aprobación: 1/12/2020. Dol: http://doi.org/10.22201/cuaieed.16076079e.2021.22.1.15 
"No hay crisis inútil"

Beatriz Oropeza Villalobos

Vol. 22, Núm. 1, enero-febrero 2021

Revista Digital Universitaria

\section{Beatriz Oropeza Villalobos}

beti.oropeza@gmail.com

orcid.org/0000-0003-4760-4111

Ingeniera Geofísica por la Universidad Nacional Autónoma de México (UnAm), con una Maestría en Ciencias en la especialidad de Vulcanología y otra en Física Educativa por el Instituto Politécnico Nacional (IPN). Fue becaria de Supercómputo, trabajó en el Instituto de Geofísica en la elaboración de un boletín informativo y también en la extinta DGSCA como asesora en visualización científica. En 2002 inició como docente en Física en el Instituto de Educación Media Superior. Ha participado en diversos cursos y talleres relacionados al ámbito educativo y cursó tres diplomados: en formación docente, en divulgación de la ciencia y en habilidades para vivir. Actualmente cursa el Doctorado en Física Educativa en el IPN.

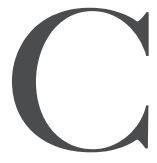
on riesgo a sonar insensible, hablaré de uno de los beneficios que nos ha dejado la pandemia. Desde hace unos años he tomado cursos sobre usos de las Tic en la educación, estrategias didácticas e incluso un seminario de investigación educativa. Sin embargo, después de la emoción que sentía por innovar en mis clases, caí en la situación de la mayoría de los docentes: mucho entusiasmo, poco tiempo, actividades urgentes. Así que la intención cayó en el olvido y seguí realizando las viejas prácticas. Quizá en el mejor de los casos incorporaba algún elemento aislado, por ejemplo, dejar de insistir a mis estudiantes que compraran una calculadora científica y solicitarles que bajaran una aplicación específica para su teléfono celular y, por supuesto, aprender yo también a utilizarla.

En abril, al término de las vacaciones y ante el escenario tan aciago, llegó la demanda de mis estudiantes —sí, los estudiantes nos alientan e impulsande seguir con las clases, pero ahora en la modalidad a distancia. Me enfrenté a una temible situación: a pesar de conocer las ventajas de las tıc en el ámbito educativo y sus fundamentos teóricos, me daba pánico empezar. ¿Qué sistema de videoconferencia usar? ¿Cómo modificar mi planeación de presencial a la de Enseñanza Remota de Emergencia (ERE, en el camino aprendí este concepto)? ¿Cuáles eran mis nuevas expectativas sobre el aprendizaje de mis estudiantes y cuáles eran las suyas hacia mí? ¿Podría manejar aceptablemente las herramientas digitales? A pesar del miedo, no tenía opción, mis alumnos me necesitaban y requerían las clases. A ellos me debo. 
Así que cerré los ojos y en medio del temor y la incertidumbre lo intenté. Tuve muchas dudas, cometí muchos errores, pero pude lograr el comienzo de un maravilloso período de aprendizaje significativo, algo acelerado pero casi autónomo. Me convertí en una docente aprendiz.

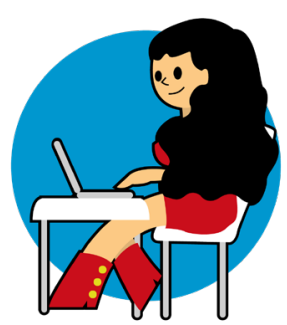

Empecé a usar redes sociales para comunicarme con mis estudiantes, aprendí a manejar diferentes sistemas de videoconferencia, abrí un sitio Moodle y uno en Classroom, cambié el pizarrón de plumón por uno electrónico, aprendí a realizar simulaciones digitales que sustituyeran las prácticas de laboratorio, mejoré mi habilidad en grabar videos, en fin..., jtodo en seis meses! Aunque no caminé sola, mi esposo, mis amigos, mis colegas, pero sobre todo mis estudiantes, me acompañaron. Quizá si hubiera tomado un año sabático y diseñado un proyecto para realizarlo en ese tiempo no hubiera aprendido tanto ni tan rápido. Definitivamente, no hay crisis inútil.

\section{Cómo CITAR ESTE ARTículo}

* Oropeza Villalobos, Beatriz. (2021, enero-febrero). No hay crisis inútil. Revista Digital Universitaria (RDU), 22(1). Dol: http://doi.org/10.22201/ cuaieed.16076079e.2021.22.1.15 